MODELING, IDENTIFICATION AND CONTROL, 1994, VOL. 15, NO. 3, 161-164

doi:10.4173/mic.1994.3.5

\title{
The Past and the Next Fifteen Years
}

\author{
MANFRED MORARI $\dagger$ \\ Keywords: Model predictive control, optimal control, control applications
}

The scope of MIC defined by the title Modeling, Identification and Control is broad and it is impossible to to justice to all these areas in a discussion which is limited to a few pages. Therefore, in the following paragraphs I will concentrate on control and leave the treatment of the other topics to the other contributors.

\section{MIC - the first 15 years}

When one looks at the articles published in MIC during the last fifteen years, one cannot help but be amazed by the wide range of control applications which are covered. Even if one forgets for a moment that this is largely the output of a single small country with a small population, it is impressive. If one takes these factors into account, it is astounding. The journal is probably the best reference on control problems related to aquaculture, covering topics such as the control of fish behaviour, automation in a lobster farming plant, the dynamics of plankton patchiness, and the planning and management of fish resources and fisheries operations. We can also learn how to take advantage of run-off prediction for the operation of a hydro-electric power station, how to control drilling vessels, distillation columns, electro-metallurgical processes and robots, in particular, an autonomous underwater vehicle. In many other journals, the word 'application' refers to the use of a mathematical model whose behaviour resembles in some way that of a real process. Applications reported in $M I C$ are either real applications (pilot plant or even full scale), or at least show direct industrial involvement implying some relevance of the study for the solution of practical problems. While many in the control field contemplate and philosophize about the gap between theory and practice, in the papers published in MIC we witness activity to close the gap or not to let it appear in the first place.

The reasons for the applications to take place and their success are to no small extent the personality and energy of the editor, Jens G. Balchen, who was responsible for the education and training of most of the authors, if not most control engineers in Norway. His well-trained engineers were capable of recognizing the engineering relevance of the theoretical developments and applying them to important practical problems. To appreciate the significance of these contributions to the development of the field, it may be worthwhile to look at the control area in general and then at a highly abbreviated history of the control of linear systems viewed from my (undoubtedly biased) personal perspective.

In control, as in all engineering disciplines, we are faced on one side with a real problem which in its complexity defies any analysis. On the other side, we have an abstracted problem which mimics certain aspects of the real problem and is amenable to a theoretical analysis and 'optimal' solution. Application of this solution of the

Received 8 March 1994.

$\dagger$ Control and Dynamical Systems, 210-41 California Institute of Technology, Pasadena, CA 91125, USA. 
abstracted problem to the real problem requires a leap of faith which is the smaller, the better the engineer is and the closer the abstracted problem is to the real problem. Progress can be characterized in terms of narrowing this gap, either by developing engineering insight into what features of the real problem need to be included in the theoretical problem or by removing some of the assumptions on which the theory is based. It is in this shaping of the engineering mind, for which the contributions reported in $M I C$ are invaluable.

\section{A brief history of control}

Regarding the theoretical developments we see, as in almost any field, short periods of breakthroughs followed by years where extensions and modifications are developed, periods of excitement where clever minds are attracted to the field, and periods of disillusionment which drive away the academic elite. The boom periods in control were all characterized by the introduction of new mathematical tools which greatly expanded the range of problems control theory can deal with and provided new fundamental insight into the trade-offs inherent in control system design.

At the dawn of the control field as a separate discipline stand the contributions of Bode (1945) and Nyquist (1932), who showed how to gain a fundamental understanding of the nature of feedback control from an application of complex variable theory. The contributions of Kalman (1960) (Kalman and Bucy 1961) in the early 1960s allowed us to tackle multivariable control problems efficiently using the newly developed state-space approach. Finally, the 1980 s were shaped by the ideas of robust control and $H_{\infty}$ control. Though the history of this decade is not written yet, it is likely that the names of Zames (1981) and Doyle (1982) (Doyle and Stein 1981) will be associated with this period. Robust control has given us tools for analysing the impact of model uncertainty on closed-loop stability and performance and has taught us how to account for model/plant mismatch in control system synthesis.

\section{A look at the future}

Where will the field go in the next fifteen years and what should the role be of $M I C$ over that time period? In the perception of many, it is unlikely that during the next decade we will see developments in linear control theory which will have the broad impact that robust control had in the last decade. There is some consensus that we will see progress on the control of nonlinear systems, not in the form of a few major discoveries, but, as should be expected from the nature of the field, in the form of many smaller contributions. The results, or at least their impact, will be limited to specific application areas, for example mechanical systems, or will address specific process nonlinearities, for example, constraints on inputs and/or outputs. Our understanding of the nature of nonlinear systems will continue to be enhanced by mathematical tools borrowed from differential geometry and differential algebra (Isidori 1989), but their direct impact is unlikely to expand beyond the study of mechanical systems.

As an example of a specific process nonlinearity, the input constraint problem, also referred to as the saturation problem, has been studied for decades but only with the help of the tools developed during the last ten years, we are discovering structural characteristics which are inherent in all successful anti-windup compensators for multivariable systems (Walgama et al. 1992, Kothare et al. 1994). At this point, the synthesis is still ad hoc but a systematic approach is within reach. 
The exponentially increasing resources for on-line computation have largely gone unrecognized by the theoreticians and most newly proposed algorithms still require little else beyond matrix and vector manipulations. A computationally more expensive approach to the constraint problem is model predictive control (Arkun and Ray 1991, Clarke 1994) where an optimization problem (linear program, quadratic program, nonlincar program) is solved in real time at each time step. The success of model predictive control is remarkable in several ways. First of all, it is a truly multivariable technique; applications with as nany as twenty inputs and forty outputs were reported. It runs counter to the belief which dominated the process industries that reliability and transparency to the operating personnel can only be achieved through a decentralized control structure. Also, for the first time, we see a dynamic control law involving extensive on-line computations and taking full advantage of the new hardware.

In many ways model predictive control points the way to the future. Complex tasks (for example, multivariable problems involving general constraints on inputs and outputs) require complex algorithms and on-line optimization is a powerful approach. For some time, these techniques have been shunned by purists who saw in them an empirical approach devised by clever engineers which lacked a theoretical foundation and any provable properties. This situation has now been changed thanks to the recent stability results by Mayne and Michalska (1990) and Rawlings and Muske (1993). Extensions are being developed to address robustness (Zheng and Morari 1993).

Even for nonlinear systems algorithms are appearing which are not only implementable with reasonable on-line effort but which also have stability and robustness guarantees. Recently, model predictive control was shown to deliver excellent performance on some nonholonomic mechanical systems (Oliveira and Morari 1994) which challenged the research community for a decade (Brockett 1983, Pomet 1992, Teel et al. 1992). It is also believed that predictive control in the form of 'fuzzy predictive control' was mainly responsible for the widely reported high quality performance of the Sendai train system where a fuzzy decision maker was put on top of a predictive control algorithm (Yasunobu 1993).

\section{An expanded role for the control engineer}

Finally, apart from all the detailed issues related to algorithms we will see the role of the control engineer further changing away from designing controllers to designing processses (Downs and Doss 1991). One major benefit of optimal control is that it tells us exactly what performance is achievable under precisly defined conditions. If this performance is inadequate, then the control analysis can point at the part of the process which must be changed (Perkins 1992, Zafiriou 1994). In a similar vein, we are starting to understand control oriented modeling as illustrated by Badmus, Eveker and Nett (1992).

\section{The future role of $M I C$}

What should the role be of $M I C$ during the next fifteen years? The journal is recognized to fulfill an important function in bringing theory and applications together which we all hope will continue. Not to look 'old fashioned' however it is essential that we see the impact of new control developments on applications. It is curious, for example, that for all practical purposes we do not find any articles in $M I C$ describing the application of the theoretical developments of the last ten years, for example, $H_{\infty}$ and $\mu$ to engineering problems. One cannot help but wonder if this is a function of the training or if there is no perceived need for these techniques. This is unfortunate 
because there is widespread agreement that many of these techniques have significantly narrowed the necessary leap of faith, have brought performance advantages to applications and have provided insight into why some traditional multivariable techniques like decoupling have failed (Morari and Zafiriou 1989). Heeding this advice, $M I C$ will continue to be a valuable resource in the future.

\section{REFERENCES}

Arkun, Y. and Ray, W. (eds) (1991). Proc. Fourth International Conference on Chemical Process Control CPCIV. South Padre Island, Texas (CACHE-AIChE).

BADMUS, O., EVEKER, K. and NETT, C. (1992). Control-oriented high frequency turbomachinery modeling. 28th Joint Propulsion Conference and Exhibit, American Institute of Aeronautics and Astronautics, Nashville, TN.

BODE, H. (1945). Network Analysis and Feedback Amplifier Design (Van Nostrand, Princeton). BROCKETT, R. W. (1983). Asymptotic stability and feedback stabilization, in R. W. Brockett, R. S. Millman and H. J. Sussman (eds), Differential Geometric Control Theory (Birkhäuser), pp. 181-191.

Clarke, D. W. (ed.) (1994). Proc. Workshop on Advances in Model-Based Predictive Control (Oxford University Press, Oxford).

Downs, J. J. and Doss, J. E. (1991). Present status and future needs: The view from North American industry, in Y. Arkun and W. Ray (eds), Proc. Fourth International Conference on Chemical Process Control CPCIV, South Padre Island, Texas, (CACHE-AIChE), pp. 53-77.

DoYLE, J. C. (1982). Analysis of feedback systems with structured uncertainties. IEE Proceedings, D, 129, 242-250.

DoyLE, J. C. and STEIN, G. (1981). Multivariable feedback design: Concepts for a classical/ modern synthesis. IEEE Trans. Aut. Contr., 26, 4-16.

IsIDORI, A. (1989). Nonlinear Control Systems (Springer-Verlag: New York).

Kalman, R. (1960). Contributions to the theory of optimal control. Bol. Soc. Mat. Mexicana, 5, $102-119$.

KaLMAN, R. and BuCY, R. (1961). New results in linear filtering and prediction theory, J. Basic Eng., Trans, ASME D, 83, 95-108.

Kothare, M., Campo, P., Morari, M. and Nett, C. (1994). A unified framework for the study of anti-windup designs. Automatica, in press.

MAYNE, D. and MICHAKSKA, H. (1990). Receding horizon control of nonlinear systems. IEEE Trans. Aut. Contr., 35, $814-824$.

Morari, M. and Zafiriou, E. (1989). Robust Process Control (Prentice-Hall, Inc., Englewood Cliffs).

NyquIST, H. (1932). Regeneration theory. Bell Syst. Tech. J., 11, 126-147.

OLIVEIRA, S. and MORARI, M. (1994) Robust model predictive control for nonlinear systems, Proc. IEEE Conf. on Decision and Control, Orlando, Florida, submitted.

Perkins, J. D. (ed.) (1992) IF AC Workshop on Interactions hetween Process Design and Process Control (Pergamon Press, London).

PoMET, J. (1992). Explicit design of time-varying stabilizing control laws for a class of controllable systems without drift. Syst. Contr. Lett., 18, 1512-1516.

RawLings, J. and MUSKe, K. R. (1993) The stability of constrained receding horizon control. IEEE Trans Aut. Contr., 38, 1512-1516.

Teel, A., Murray, R. and WALSH, G. (1992). Nonholonomic control systems: From steering to stabilization with sinusoids. Proc. IEEE Conf. on Decision and Control, pp. 1603-1609.

WALGAMA, K. S., RöNNBÄCK, S. and STERNBY, J. (1992). Generalization of conditioning technique for anti-windup compensators, IEEE Proc. D, 139, 109-118.

YASUNOBU, S. (1993). Fuzzy control methods and their real system applications, IMA Minisymposium on Fuzzy Control, The Institute for Mathematics and its Applications, Minneapolis, MN, unpublished.

Zafiriou, E. (ed.) (1994). IF AC Workshop on Integration of Process Design and Process Control (Baltimore: Pergamon), in press.

ZAMES, G. (1981). Feedback and optimal sensitivity: Model reference transformations, multiplicative seminorms, and approximatc inverses. IEEE Transactions on Automatic Control, 26, 301-320.

ZHENG, A. and MORARI, M. (1993). Robust stability of constrained model predictive control. Proc. American Control Conf., San Francisco, California, pp. 379-383. 